\title{
The Effect of Triazole on Cysteine Biosynthesis in Salmonella typhimurium
}

\author{
By DANUTA HULANICKA AND T. KLOPOTOWSKI \\ Institute of Biochemistry and Biophysics, Polish Academy of Sciences, \\ Warsaw I2, Poland \\ AND D. A. SMITH \\ Department of Genetics, University of Birmingham, Birmingham, I5 \\ (Accepted for publication 24 April 1972) \\ SUMMARY
}

\begin{abstract}
The inhibition by triazole of the growth of wild-type Salmonella typhimurium is reversed by serine, methionine or cysteine. Two auxotrophs which responded to any one of these three compounds were hypersensitive to triazole and were shown by genetical analysis and enzyme assays to have a $c y s E$ (serine transacetylase) deficiency. Triazole hypersensitivity of the mutants was reversed by sulphite and sulphide and triazole prevented induction of sulphate permease and activating enzymes by $O$-acetyl serine (OAS) or serine in the wild-type. It is probable that the inhibitory effect of triazole is due to this interference with the induction of cysteine biosynthetic enzymes.
\end{abstract}

\section{INTRODUCTION}

In Salmonella typhimurium the formation of cysteine from sulphide and $O$-acetylserine (OAS) involves the convergence of two pathways (Smith, I97I ; Fig. I). Sulphate is taken up and reduced in four steps to give sulphide and OAS is formed from serine and acetyl CoA (serine transacetylase). Cysteine is involved in methionine synthesis: it reacts with $O$ succinylhomoserine to give cystathionine, which is then hydrolysed to give homocysteine, the immediate precursor of methionine. Regulation of cysteine synthesis results from feedback inhibition of the sulphate transport system and serine transacetylase and nonco-ordinate repression of all the other cysteine enzymes by cysteine. There is also evidence for induction control of cysteine enzymes for which OAS and the cysB (regulatory) gene product are necessary (Jones-Mortimer, I969 $b$ ).

Boguslawski, Walczak \& Klopotowski (1967) reported that I,2,4-triazole inhibited the growth of Salmonella typhimurium, and that this inhibition could be overcome by adding serine, methionine or cysteine to the growth media. We have isolated mutants which grow poorly unless provided with serine, methionine or cysteine. We have shown that these mutants have lowered serine transacetylase activity due to a mutation in the cysE gene. Triazole is shown to interfere with the induction process possibly due to a reduction in the intracellular level of the inducer OAS.

\section{METHODS}

Organisms. All bacteria used were derivatives of Salmonella typhimurium strain LT2 (Table I). Map locations of their markers are included in Fig. 2. The transducing phage was the L4 mutant of phage P22 (Smith, 1968). 


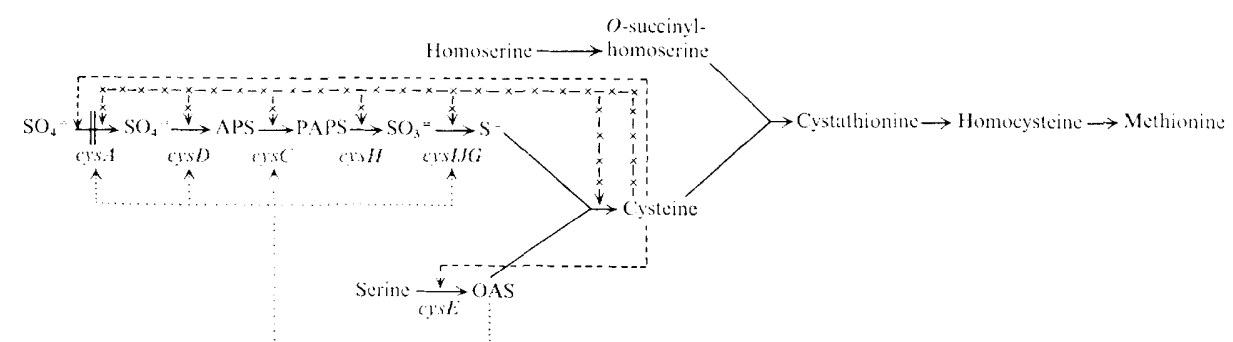

Fig. I. Outline of the synthesis of cysteine and its relation to methionine synthesis in Salmonella typhimurium. APS, adenosine-5'-sulphatophosphate; PAPS, adenosine- $3^{\prime}$-phosphate 5 'sulphatosphosphate; OAS, $O$-acetylserine cys $A$, sulphate permease; $c y s C$, ATP-adenylylsulphate $5^{\prime}$-phosphotransferase (APS kinase); cys $D$, ATP sulphate adenylyl transferase (ATP sulphurylase); cys $E$, serine transacetylase; $c y s H$, adenosine $3^{\prime}$-phosphate $5^{\prime}$-sulphatophosphate reductase (PAPS reductase); cysGIJ, hydrogen sulphide NADP oxidoreductase (sulphite reductase). -- $\rightarrow$ Feedback inhibition: $\cdots \cdots>$ induction; $x-x-x \rightarrow$ repression (after Smith, 1971).

\section{Table I. Strains of Salmonella typhimurium}

The genotype designations are in accordance with Sanderson (1970): arg, arginine; cys, cysteine; his, histidine; $i l v$, isoleucine-valine; lac, lactose; met, methionine; pur, purine; pyr, pyrimidine; and trp, tryptoptan.

\begin{tabular}{|c|c|c|}
\hline $\begin{array}{c}\text { Strain } \\
\text { designation }\end{array}$ & Genotype & Source \\
\hline & wild-type LT2 & P. E. Hartman \\
\hline & $\operatorname{argEII6}$ & K. E. Sanderson \\
\hline & cysE 396 & K. E. Sanderson \\
\hline & pyrEI25 & K. E. Sanderson \\
\hline SMC-I & cysEr 353 metK $731\left(P_{22}\right)$ & $\begin{array}{l}\text { K. F. Chater } \\
(\mathrm{NG} \text { mutagenesis of } \\
\left.\text { met } K_{73 I}\left(\mathrm{P}_{22}\right)\right)\end{array}$ \\
\hline SMC-2 & cysEI 354 hisCBHAFIE35or HfrK 5 & $\begin{array}{l}\text { K. Krajewska-Grynkiewicz } \\
\text { (DES* mutagenesis of } \\
\text { Tw30I) }\end{array}$ \\
\hline TRII 7 & $\operatorname{trpCrO} \mathrm{F}^{\prime} \mathrm{lac}^{+}$ & J. R. Roth \\
\hline TW293 & purFI45 hisCBHAFIE35OI $\mathrm{HfrK}_{5}$ & W. Walczak \\
\hline TW3OI & hisCBHAFIE350I $\mathrm{HfrK}_{5}$ & $\begin{array}{l}\text { Transduction of Tw } 293 \\
\text { with wild type. }\end{array}$ \\
\hline Tw338 & cysEI353 ilv-666 metK $731\left(\mathrm{P}_{22}\right)$ & $\mathrm{NG}^{*}$ mutagenesis of SMC-I \\
\hline TW339 & cysEI353 ilv-666 metK 731 (P22) F'lac ${ }^{+}$ & $\begin{array}{l}\text { Episome transfer from } \\
\text { TRII } 7 \text { to TW } 338\end{array}$ \\
\hline TW340 & cysEI 353 & - \\
\hline
\end{tabular}

Culture media. Sulphur-free minimal medium (BS) was the medium C of Vogel \& Bonner (1956) in which magnesium sulphate was replaced by magnesium chloride. Ammonium sulphate or L-cysteine were added to final concentrations of $0.1 \mathrm{mM}$, and glucose to $0.2 \%$. Medium $\mathrm{L}$ comprised medium $\mathrm{C}(\mathrm{pH} 7)$ without citric acid, containing lactose at a final concentration of $0.5 \%$. For the growth of auxotrophs, adenine $(0.2 \mathrm{~mm})$ with thiamin (O.0I $\mathrm{mM}$ ) and amino acids (O.I $\mathrm{mM}$ ) except for L-serine (I $\mathrm{mM}$ ) were added. Solid media were made by the addition of $2 \%$ agar.

Culture conditions. Liquid cultures were grown at $37{ }^{\circ} \mathrm{C}$ with aeration and their growth followed turbidimetrically at $420 \mathrm{~nm}$ in a Unicam SP500 spectrophotometer. Extinction measurements were converted to $\mu \mathrm{g}$ dry wt.

Phage lysates. Log phase bacteria in Biomed (Poland) broth medium were infected with 


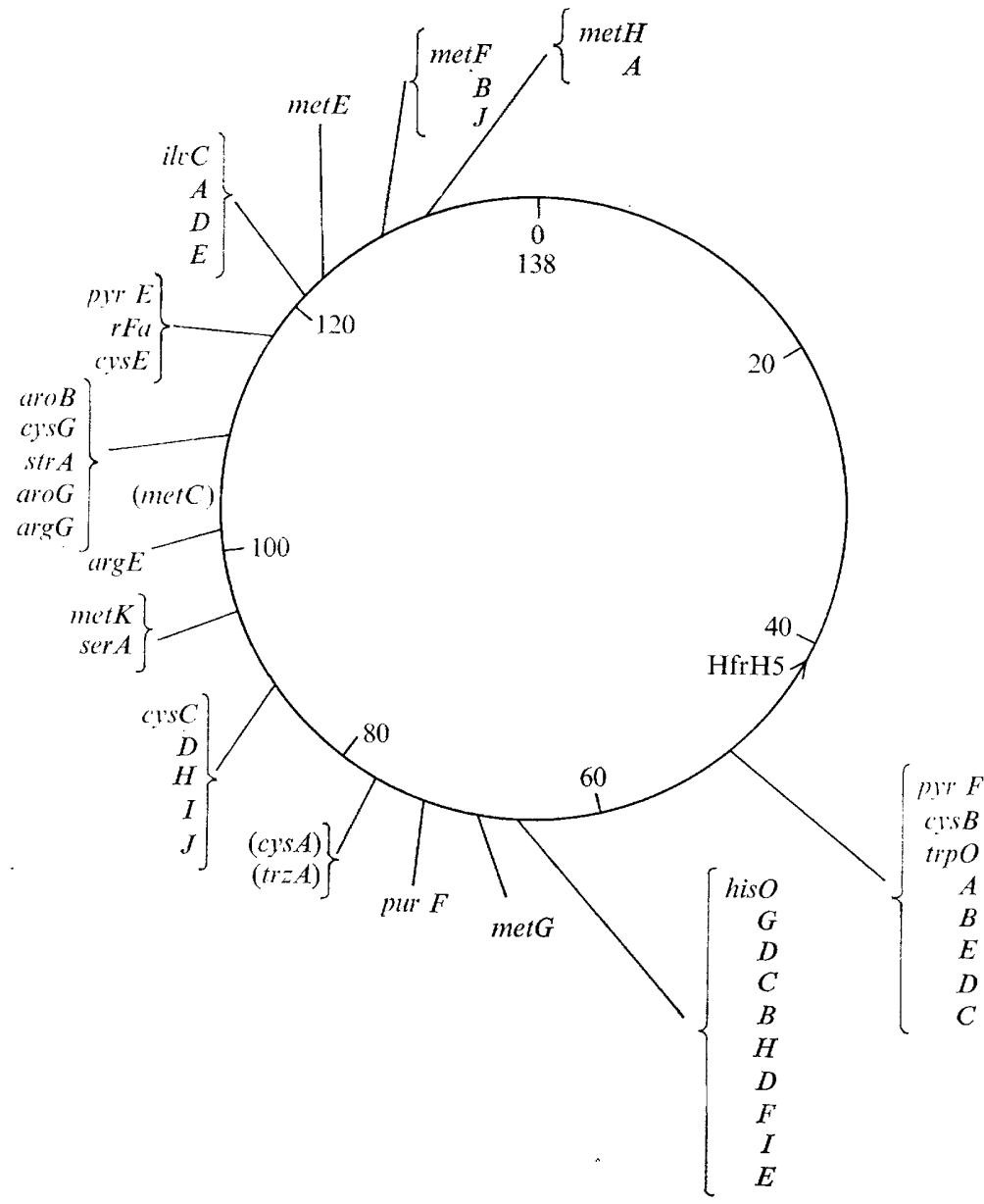

Fig. 2. Part of the linkage map of Salmonella typhimurium. Map positions, I to I $38 \mathrm{~min}$, are indicated at 20-min intervals. \{, Transduction fragment; $\{1$, transduction fragment, orientation unknown; ( ), precise location unknown. Gene designation as in Table I with the following additions: aro, aromatic; $r f a$, rough; ser, serine; $s t r$, streptomycin; $t r z$, triazole resistance.

phage $\mathrm{L}_{4}$ at a multiplicity of $\mathrm{O} \cdot \mathrm{I}$, and incubation continued for 8 to $\mathrm{I} 8 \mathrm{~h}$ until lysis. Bacterial debris was removed by centrifuging at $6600 \mathrm{~g}$, and phage sedimented by centrifuging for $50 \mathrm{~min}$ at $32000 \mathrm{~g}$. Phage pellets were resuspended in $\mathrm{C}$ medium after soaking for $2 \mathrm{~h}$; chloroform (one twentieth final volume) was then added to the suspensions which were kept at $4{ }^{\circ} \mathrm{C}$.

Transduction. Quantities (O.I $\mathrm{ml}$ ) of overnight bacterial cultures in broth infected with phage at a multiplicity of at least 5 were spread on selective solid medium and incubated for $48 \mathrm{~h}$ at $37^{\circ} \mathrm{C}$.

Mutagenesis. Tenfold dilutions of overnight broth cultures of bacteria in fresh broth $+\mathrm{N}$ methyl- $N^{\prime}$-nitro- $N$-nitrosoguanidine (NG) at $25 \mu \mathrm{g} / \mathrm{ml}$ were incubated for $30 \mathrm{~min}$ at $37^{\circ} \mathrm{C}$ and appropriate dilutions spread on nutrient agar to give single colonies. After incubation auxotrophy was tested by replica plating.

Assay of sulphate permease. The method was similar to that of Dreyfuss \& Pardee (1966) except that cell separation was carried out on Sephadex columns rather than by membrane filtration. Log phase bacteria were washed twice and resuspended in BS medium. The 
incubation mixture contained in a final volume of $0.5 \mathrm{ml}, 25 \mathrm{nmol}$ sodium sulphate, $\mathrm{I} 5 \mu \mathrm{g}$ chloramphenicol, I mg glucose, $5 \mathrm{mg}$ dry wt of bacteria and $\mathrm{I} \cdot 25 \mu \mathrm{Ci}$ of carrier-free $\left[{ }^{35} \mathrm{~S}\right]$ sodium sulphate. After $5 \mathrm{~min}$ shaking at $2 \mathrm{I}{ }^{\circ} \mathrm{C}$ this mixture was passed quickly through Sephadex $\mathrm{G}_{50}$, coarse mesh; the bed volume was $6 \mathrm{ml}$. Bacteria usually passed through the column in less than $30 \mathrm{~s}$. Unabsorbed $\left[{ }^{35} \mathrm{~S}\right]$ sulphate never appeared earlier than in the sixth drop. The first three drops of turbid bacterial suspension were collected, diluted and their extinction measured in the spectrophotometer at $420 \mathrm{~nm}$ before conversion to $\mu \mathrm{g}$ dry weight of cells. Radioactivity was measured in a Nuclear Chicago Biospan gas flow windowless counter.

Assay of sulphate-activating enzymes. This was based on the method of Pasternak (I962). Log phase bacteria were washed and resuspended in $100 \mathrm{nM}$-tris- $\mathrm{HCl}$ buffer $(\mathrm{pH} 8.0)$ containing $5 \mathrm{~mm}$-EDTA and disrupted by sonication. After centrifugating at $10000 \mathrm{~g}$ for $\mathrm{I} \mathrm{h}$ the extract was passed through a Sephadex G50 column equilibrated with tris buffer and further centrifuged at $105000 \mathrm{~g}$. The incubation mixture contained in a volume of $0.5 \mathrm{ml}$ : sodium ATP, $3 \mu \mathrm{mol}$; magnesium chloride, $3.7 \mu \mathrm{mol}$; potassium sulphate, $0.3 \mu \mathrm{mol}$; carrier-free $\left[{ }^{35} \mathrm{~S}\right]$ sodium sulphate, $\mathrm{I} 0 \mu \mathrm{Ci}$; tris- $\mathrm{HCl}$ buffer, $\mathrm{pH} 8.0,25 \mu \mathrm{mol}$; and 0.12 to $\mathrm{I} \cdot 25 \mathrm{mg}$ extract protein. Reactions were stopped after $30 \mathrm{~min}$ of incubation at $2 \mathrm{I}{ }^{\circ} \mathrm{C}$ by boiling for $2 \mathrm{~min}$. For controls either ATP or the bacterial extract was omitted. Following centrifuging at $6600 \mathrm{~g}$ the supernatants were mixed with $90 \mathrm{mg}$ of activated charcoal in $2 \mathrm{ml}$ of $100 \mathrm{~mm}$-sodium acetate buffer $(\mathrm{pH} 5 \cdot 8)$ containing $30 \mathrm{~mm}$-sodium sulphate. (It was found that under these conditions Io $\mu \mathrm{mol}$ of ATP as a model adenosine compound could be adsorbed by the charcoal.) After ro min the suspensions were passed through membrane filters (Biomed Coli 5, average pore size $0.5 \mu \mathrm{m}$ ), the deposited charcoal washed extensively with acetate buffer and the radioactivity on the filters counted with a thin mica window Geiger-Muller tube. The c.p.m. obtained were from an infinitely thick sample layer. A linear relationship between the radioactivity and quantity of the samples was obtained over the range 0.12 to $I \cdot 2 \mathrm{mg}$ protein.

In an alternative method the enzymes were assayed in bacteria which had been washed with tris buffer and shaken with $10 \mu \mathrm{l}$ toluene $/ \mathrm{ml}$ for $15 \mathrm{~min}$ at $37^{\circ} \mathrm{C}$.

Assay of serine transacetylase. The method of Kredich \& Tomkins (1966) was used.

Protein determination. The protein in cell-free extracts was determined by the method of Lowry, Rosebrough, Farr \& Randall (I95I).

Chemicals. $O$-acetyl-L-serine (OAS) was synthesized by the method of Wiebers \& Garner (I967). All other chemicals used were commercial products; disodium ATP (Sigma Chemical Co. St Louis, Missouri, U.S.A.), acetyl-Co-enzyme A (Mann Research Laboratories, New York, U.S.A.), L-amino acids and I,2,4-triazole (Calbiochem, Los Angeles, California, U.S.A.), 3-amino-I,2,4-triazole (Fluke, Buchs, Poland), carrier-free $\left[{ }^{35}\right.$ S]sodium sulphate (Instytut Badan Jadrowych, Swierk, Poland), and chloramphenicol (Polfa, Warsaw, Poland).

\section{RESULTS}

Origin and properties of serine, methionine or cysteine $(S M C)$ mutants.

Two mutants requiring either serine, methionine or cysteine for growth, SMC-I and SMC-2 (Table I) have been studied. SMC-I grows slowly whereas SMC-2 does not grow at all on unsupplemented minimal agar medium. In each case the growth on this medium is stimulated by either serine, methionine or cysteine. The growth characteristics of SMC-I and SMC-2 in supplemented and unsupplemented BS medium appear in Fig. 3 and 4. SMC-I can grow on sulphate-supplemented medium but only after a lag lasting 2 to $3 \mathrm{~h}$ but the 


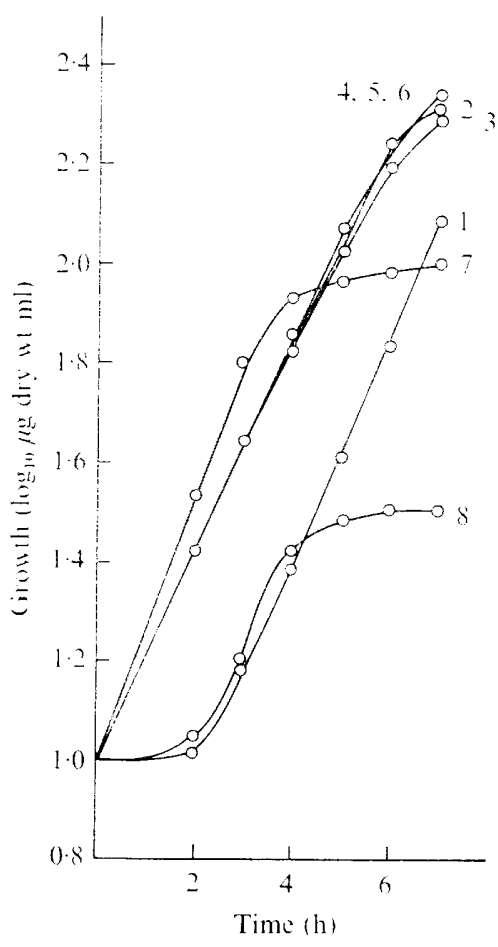

Fig. 3

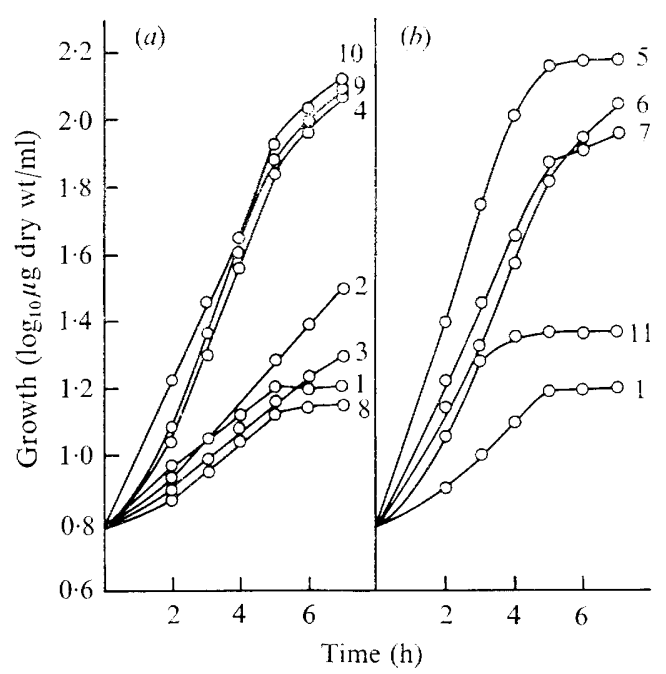

Fig. 4

Fig. 3. Growth responses of strain SMC-I (cysEI 353). BS medium was inoculated with a washed bacterial suspension previously grown in BS medium + cysteine (0.I mM) to a final density of Io $\mu \mathrm{g} / \mathrm{ml}$. All supplements were at final concentration of $0 \cdot \mathrm{I} \mathrm{mM}$ except for serine (I mM): curve I, sulphate; 2 , sulphite; 3 , sulphide; 4 , sulphate + serine; 5 , cysteine; 6 , sulphate + methionine; 7 , methionine; 8 , no addition.

Fig. 4. Growth responses of strain SMC-2 (cysEI 354). Conditions were as for Fig. I except that BS medium was inoculated to a final density of $8 \mu \mathrm{g} / \mathrm{ml}$. Curve I, sulphate; 2, sulphite; 3, sulphide; 4, sulphate+serine; 5 , cysteine; 6 , sulphate+methionine; 7 , methionine; 8 , no addition; 9 , sulphite + serine; I0, sulphide + serine; I I, serine.

addition of serine to the medium completely eliminates this lag, which is therefore perhaps due to inability to convert exogenous sulphate into endogenous sulphite because of slow accumulation of OAS necessary for induction of the cysteine enzymes. In contrast SMC-2 cannot utilize sulphate without serine; residual growth in the presence of sulphate was not very different from that in unsupplemented medium. This residual growth probably results from utilization by the bacteria of their internal pool of cysteine. Further growth following the addition of serine suggested that BS medium may contain traces of a sulphur compound or that endogenous pools of these compounds were present. The latter assumption seems more plausible as residual growth even occurred in BS medium which had already been used for the growth of bacteria.

SMC-I and SMC-2 also differed from each other in their growth responses to sulphite and sulphide; SMC-I grew on sulphite or sulphide, but SMC-2 also required serine to give similar growth responses. This suggested that SMC-2 was deficient in cysteine biosynthesis and, in fact, the specific activity of sulphite reductase in cell-free extracts of SMC-2 was less than I \% of that in wild-type extracts. 


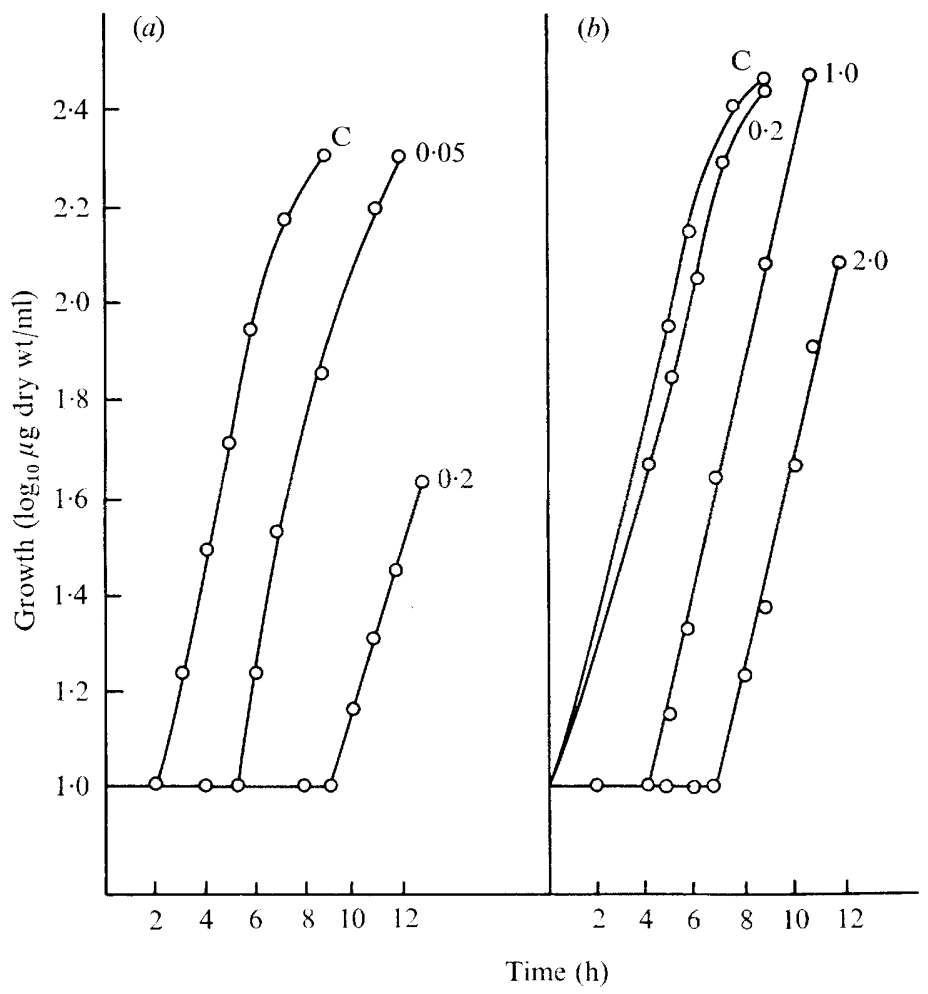

Fig. 5. Sensitivity of SMC-I (cysEI353) to triazole. BS medium +sulphate (O.I mM) was inoculated with washed bacteria grown in BS medium + cysteine (O.I mM). The concentrations of inhibitor added are indicated on the curves in $\mathrm{mM} / \mathrm{l}$. C, control without triazole. (a) SMC-I (cysEI 353); (b) wild-type.

The presence of cysteine or methionine in BS medium permitted the same rate of growth of both strains but total growth with cysteine was greater in both cases. It may be that growth on methionine as a source of sulphur only results from the sparing of cysteine. The addition of sulphate to BS + methionine medium did not stimulate further growth of either mutant. Stimulation of growth of the SMC mutants by cysteine and its precursors suggests that these strains are deficient in the biosynthesis of this amino acid.

\section{Hypersensitivity of SMC-I to triazole}

The reversal of triazole inhibition by serine, methionine or cysteine (Boguslawski et al. I967) suggests that the inhibitor and the SMC defect both affect cysteine biosynthesis and that if so the cysteine deficiency of SMC mutants might result in hypersensitivity to triazole. Thus the triazole sensitivity of SMC-I (Fig. $5 a$ ) was compared with that of wild-type (Fig. $5 b$ ). It can be seen that 0.2 mM-triazole caused inhibition of the growth of SMC-I for $9 \mathrm{~h}$ but did not noticeably affect the growth of wild-type. However, this increased triazole sensitivity of SMC-I does not necessarily mean that triazole affected the same cytoplasmic product which is defective in the mutant. It is possible that the SMC mutations and triazole affect two different factors involved in the same process. 
Table 2. Serine transacetylase activities

Wild-type, cysEI 353 and $c y s E_{1} 354$ were grown in $\mathrm{BS}$ medium $+\mathrm{Na}_{2} \mathrm{SO}_{4}(\mathrm{O} \cdot \mathrm{I} \mathrm{mM})$ and serine (I mM) and cysE 396 in BS medium + cysteine (O.I mM). Bacteria were harvested in the log phase and their enzyme activities determined in cell free extracts.

Strain $\quad \begin{gathered}\text { Specific activity } \\ (\mu \mathrm{mol} / \mathrm{mg} \text { protein } / \mathrm{min})\end{gathered}$

Wild-type

SMC-I (cysEI 353)

SMC-2 (cysEI354)

cysE396

$\mathbf{I} 3.3$
$2 \cdot 4$
0.74
0.0

$3 \cdot 3$

$0 \cdot 74$

$0 \cdot 0$

Relative
specific activity
I00
I9
6
I

\section{Genetic map location of SMC mutations}

We have mapped the SMC mutations to see whether they coincide with any of the serine, cysteine and methionine structural genes already located on the Salmonella typhimurium linkage map (Fig. 2; Sanderson 1970). The mutation in SMC-I was identified by its hypersensitivity to triazole. As SMC-I was lysogenic for P22 conjugation was used for genetical analysis. Strain TW338 derived from SMC-I carries an NG-induced ilv mutation (Table I). It was infected with the $\mathrm{F}_{\text {ts }}^{\prime} l a c^{+}$episome (strain Tw339). The episome can integrate into any region of the $S$. typhimurium chromosome and initiate transfer to $\mathrm{F}^{-}$strains (Anton, 1968). Strain TW339 was then crossed on serine-supplemented plates with a range of auxotrophic recipients three of which gave prototrophic recombinants with the SMC phenotype when tested by replication to plates containing 2 mM-triazole; all cysE $396^{+}, 80 \%$ pyrEI $25^{+}$ and $20 \% \operatorname{argEII} 6^{+}$recombinants were triazole hypersensitive. One of the triazolehypersensitive $p y r E^{+}$recombinants (TW340) was isolated, purified by several single colony re-isolations and studied in some detail. It grew poorly on BS medium unless serine, methionine or cysteine was added. The similarity of growth pattern between this strain, other transductants and SMC-I indicated that the met $K$ mutation of SMC-I did not influence the SMC phenotype.

Strain TW340 was then used as a donor to transduce pyrEI25 and cysE596. Recombinants were selected on $\mathrm{BS}+$ serine medium and the triazole hypersensitivity of 200 recombinants of each cross tested. No pyrE $E^{+}$recombinants had the SMC phenotype but 197 cys $E^{+}$ recombinants did, which indicated $96.5 \%$ co-transduction of SMC-I with cysE. In a similar cross between cysE396 and SMC-2 when 100 recombinants were screened, $98 \%$ co-transducibility was obtained.

These results strongly suggested that the SMC phenotype could result from mutation in the cysE gene which codes for serine transacetylase (Kredich, Becker \& Tomkins, 1969).

\section{The serine transacetylase activity of SMC mutants}

Extracts of wild-type, SMC-I, SMC-2 and a representative cysE mutant were assayed (Table 2). The wild-type specific activity ( $\mathrm{I} 3.3 \mathrm{nmol}$ acetyl-CoA hydrolysed/mg protein/min) was lower than that reported for Escherichia coli в by Kredich \& Tomkins (1966). However, in another experiment a Michaelis constant for serine of $0.5 \mathrm{mM}$ was obtained with a crude cell-free extract of wild-type. This was close to the value of $0.56 \mathrm{~mm}$ obtained by Kredich \& Tomkins with their purified preparation. Both SMC strains had low serine transacetylase specific activities. In SMC-I there was an $80 \%$ and in SMC-2 a $90 \%$ reduction. The Michaelis constant for serine as determined in cell-free extracts of SMC-I and SMC-2 was I MM, slightly higher than that for wild-type. 


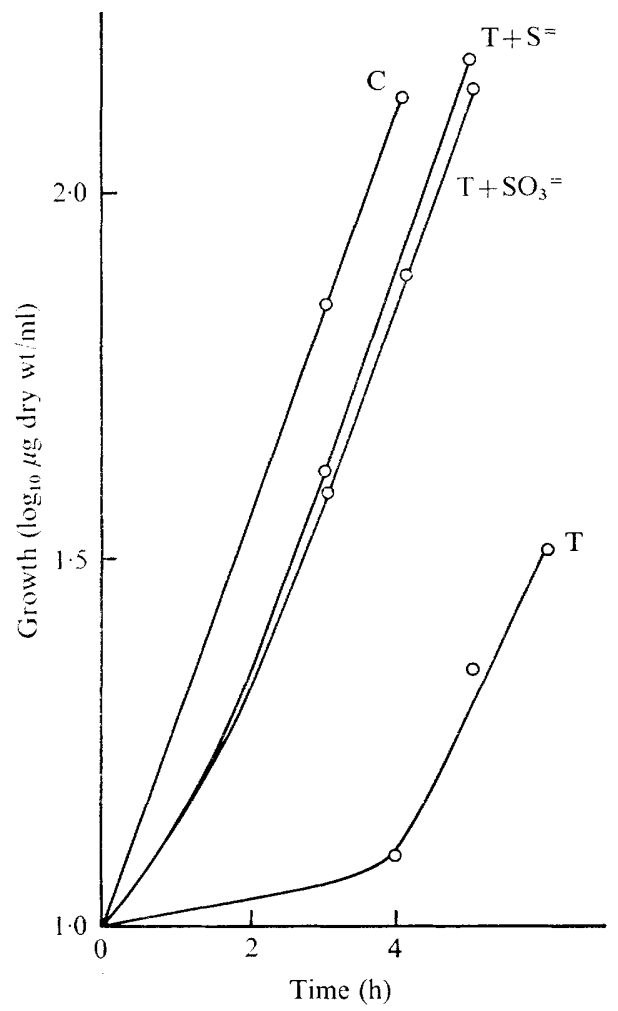

Fig. 6. Reversal of triazole inhibition of SMC-I (cysEI353) by sulphite or sulphide. BS medium + sulphate was inoculated with washed bacterial suspension to a final density of $10 \mu \mathrm{g} / \mathrm{ml}$. The concentration of triazole was $2 \mathrm{~mm}$ and of sulphite and sulphide $0 . \mathrm{I} \mathrm{mM}$. T, triazole; C, control without triazole.

These results in conjunction with the genetical data permit the designation of SMC-I and SMC-2, cysEI353 and 1354 respectively.

\section{Reversal of triazole inhibition by sulphite and sulphide}

The growth requirements of SMC-I (cysEI353), its hypersensitivity to triazole and its cysE gene deficiency suggested that triazole could interfere with cysteine biosynthesis. An attempt was therefore made to relieve triazole inhibition with cysteine intermediates. It is evident from Fig. 6 that triazole inhibition of SMC-I (cysEr 353) can be reversed by either sulphite or sulphide. This could have been the result of interaction between these anions with the triazole ring. If this had occurred the inhibition of growth of wild-type Salmonella typhimurium by 3-amino-I,2,4-triazole which interferes with histidine and purine biosynthesis (Hilton, Kearney \& Ames, I965; Hulanicka, Klopotowski and Bagdasarion, I969), should also have been reversed by these anions. No such reversal was obtained suggesting that the effect of the two sulphur compounds was more likely to have been directly concerned with cysteine biosynthesis. Triazole could inhibit a step in the cysteine pathway prior to sulphite formation or interfere with cysteine regulation. 
Table 3. Prevention of the induction of cysteine enzymes of wild-type bacteria by triazole

Log phase bacteria were grown in BS medium $+\mathrm{Na}_{2} \mathrm{SO}_{4}$ ( I mм) and OAS ( I mm), serine (I $\mathrm{mM})$ or triazole $(2 \mathrm{mM})$ as indicated.

$\begin{array}{lcc}\begin{array}{c}\text { Growth medium } \\ \text { supplement }\end{array} & \begin{array}{c}\text { Sulphate permease } \\ \text { (nmol [ }{ }^{35} \text { S]sulphate } \\ \text { mg dry wt/min) }\end{array} & \begin{array}{c}\text { Sulphate-activating } \\ \text { enzymes } \\ \text { (c.p.m.) }\end{array} \\ \text { None } & 0.42 & 785 \\ \text { OAS } & 0.70 & 7708 \\ \text { Triazole } & 0.35 & 707 \\ \text { OAS+triazole } & 0.5 \mathrm{I} & \text { I I } 36 \\ \text { None } & - & 285 \\ \text { Serine } & - & \text { I } 548 \\ \text { Serine+triazole } & - & 484\end{array}$

Table 4. The activity of the cysteine enzymes of wild-type bacteria in the presence of triazole or selenate

Bacteria were grown in BS medium $+\mathrm{Na}_{2} \mathrm{SO}_{4}$ ( $1 \mathrm{~mm}$ ). Triazole (10 $\mathrm{mm}$ ) and $\mathrm{Na}_{2} \mathrm{SeO}_{4}(2 \mathrm{~mm}$ ) were added to the reaction mixtures which contained protein at a final concentration of $0.25 \mathrm{mg} / 0.5 \mathrm{ml}$. The activities quoted are the average of two independent assays each carried out in duplicate.

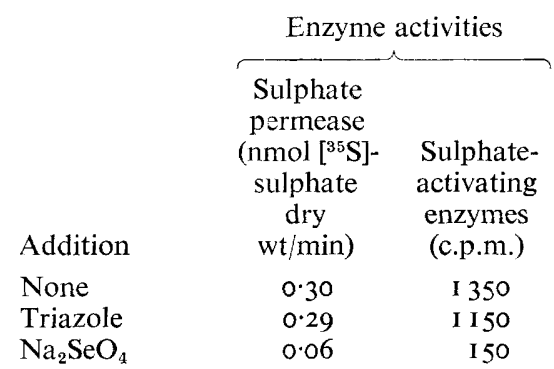

Prevention of the induction of cysteine enzymes by triazole

In preliminary experiments the growth inhibitory effect of triazole could be reversed by $O$-acetyl-serine (OAS) which suggested that the inhibitor could interfere with induction of cysteine biosynthetic enzymes (Jones-Mortimer, $1969 b$ ). Identical log phase cultures of wild-type were supplemented with OAS, serine, or either compound + triazole. After $2 \mathrm{~h}$ the bacteria were harvested and assayed for sulphate permease and the sulphate-activating enzymes (Table 3). OAS-induced sulphate permease nearly twofold but triazole added with the inducer more than halved the induction. A more striking effect was obtained with the sulphate-activating enzymes. OAS or serine was used as an inducer; OAS caused about a tenfold increase of the enzymes and triazole almost completely prevented the induction. Induction with serine was less than with OAS but again triazole almost eliminated it.

Triazole only slightly inhibited the activity of the enzymes assayed (Table 4), whereas sodium selenate, a substrate analogue known to inhibit the $c y_{s} D$ (ATP sulphurylase) enzyme (Pasternak, I962; Qureshi, I97I), inhibited both enzymes by about 80\%. This would indicate that the triazole effect upon Salmonella typhimurium is unlikely to be due to inhibition of an enzyme and so supports the deduction that it interferes with the regulation of synthesis of cysteine enzymes. 


\section{DISCUSSION}

Growth requirements for serine, methionine or cysteine in strains of Salmonella typhimurium can result from leaky cysE mutations or the presence of triazole in the growth medium of wild-type organisms and it is of interest to explore the elements common to both phenomena.

The mutants cysEr353 and Er 354 have lower intracellular levels of serine transacetylase (Table 2) and may thus contain less OAS. OAS is required to induce the enzymes of sulphate assimilation, sulphate permease, two sulphate activating enzymes and sulphite reductase. It is also an intermediate in cysteine biosynthesis (Jones-Mortimer, I969a, $b$ ). These two processes could require different concentrations of OAS. Since cysEr353 has a higher serine transacetylase activity than cysEI 354 and can utilize sulphite and sulphide (Fig. 3,4) it is inferred that cysEr 353 has enough OAS for cysteine synthesis but not enough to induce the cysteine enzymes. This limits growth of the mutant. In contrast, cysEr 354 is unable to grow on sulphite suggesting that it has insufficient OAS for both synthesis or induction. The behaviour of both mutants suggests that induction of the sulphate assimilation enzymes can only occur when OAS transsulphurylase is saturated with OAS.

Both mutants can utilize sulphate in the presence of serine (Fig. 3; 4). This is probably due to an increased intracellular concentration of serine, the substrate for serine transacetylase. This is supported by the observation that addition of serine increased the specific activities of OAS-inducible enzymes (Table 3). The growth responses of cysEI353 and EI 354 to methionine in the absence of other sulphur compounds (Fig. $3 ; 4$ ) is probably partly due to a sparing effect upon cysteine utilization. As it is generally assumed (Roberts et al. 1963) that methionine cannot serve as the sole source of sulphur for enteric bacteria, the extent of the growth response of these mutants to methionine is puzzling.

Growth inhibition by triazole is transient (Fig. 5;6) and reversed by sulphite or sulphide (Fig. 6). This resembles the growth response pattern of $c y s E_{1353}$ implying that triazole limits the rate of serine transacetylation or inhibits the use of OAS in induction. Certainly triazole has no inhibitory effect upon the activity of the cysteine enzymes in crude cell-free preparations (Table 4). It has been found (T. Klopotowski, unpublished) that triazole hydrolyses acetyl-CoA non-enzymatically and if such a reaction reduced substantially the intracellular concentration of acetyl CoA, cysteine biosynthesis could be affected. On the other hand the observation that triazole was able to prevent induction of sulphur assimilation enzymes by OAS (Table 3) argues against the idea of the main inhibitory effect of triazole resulting from hydrolysis of acetyl-CoA or from some other effect on OAS synthesis.

The mechanism of OAS induction is unknown but since $c y s B$ mutants are repressed for all cysteine enzymes, a $c y s B$ gene product could be essential for OAS induction (JonesMortimer, $1969 a ; b)$. Kredich et al. (1969) found that OAS activated a serine transacetylase/ OAS transsulphurylase complex. They considered that OAS could act as an inducer by combining with this complex. Triazole interference is not obviously related to either of these explanations, but triazole could be used for obtaining more information on how the enzymes of sulphur assimilation are induced.

Boguslawski et al. (1967) suggested that triazole inhibition of wild-type Salmonella typhimurium resulted from interference with $\mathrm{C}_{1}$ metabolism on the basis of their observation that glycine potentiated triazole inhibition. One important difference between cysEr 353 and triazole inhibited wild-type bacteria is that glycine has no effect on the mutant. Thus the present experiments appear to have no direct bearing on involvement with $\mathrm{C}_{1}$ metabolism. Although it is felt that the triazole effect is concerned with cysteine biosynthesis, the 
precise cause of cysteine deficiency in triazole-inhibited $S$. typhimurium remains to be determined.

The technical assistance of Mrs W. Chabros and financial support from the U.S. Department of Agriculture, grant FG-PO-I9I in Poland is gratefully acknowledged. The work in England was supported by the Science Research Council, and a travel grant from the Wellcome Trust to D.A.S. facilitated the final stages of collaboration.

\section{REFERENCES}

Anton, D. (1968). Histidine regulatory mutants of Salmonella typhimurium. V. Two new classes of histidine regulatory mutants. Journal of Molecular Biology 33, 533-546.

BoguslaWski, J., WALCZAK, W. \& KLOpOtOWSKI, T. (I967). Reversal by serine and potentiation by glycine of the inhibitory effect of I,2,4-triazole on growth of Salmonella typhimurium. Acta biochimica polonica I4, I33-I4I.

Dreyfuss, J. \& PARdeE, A. B. (1966). Regulation of sulphate transport in Salmonella typhimurium. Journal of Bacteriology 9I, 2275-2280.

Hilton, J. L., KeArney, P. C. \& Ames, B. N. (1965). Mode of action of the herbicide, 3-amino-I, 2,4-triazole (Amitrole); inhibition of an enzyme of histidine biosynthesis. Archives of Biochemistry and Biophysics 112, 562-566.

Hulanicka, D., Klopotowski, T. \& Bagdasarian, G. (1969). Inhibition of aminoimidazole ribotide biosynthesis in Salmonella typhimurium by aminotriazole. Acta biochimica polonica 16, $127-133$.

Jones-Mortimer, M. C. (I969a). Positive control of sulphate reduction in Escherichia coli. Isolation, characterisation and mapping of cysteineless mutants of E. coli KI 2. Biochemical Journal Iro, 579-595.

Jones-Mortimer, M. C. (1969b). Positive control of sulphate reduction in Escherichia coli. The nature of the pleiotropic cysteineless mutants of E. coli KI2. Biochemical Journal Iro, 597-602.

Kredich, N. M., Becker, M. A. \& Tomkins, G. M. (I969). Purification and characterisation of cysteine synthetase, a bifunctional protein complex, from Salmonella typhimurium. Journal of Biological Chemistry 244, 2428-2439.

Kredich, N. M. \& Tomkins, G. H. (I966). The enzymic synthesis of L-cysteine in Escherichia coli and Salmonella typhimurium. Journal of Biological Chemistry 24I, 4955-4965.

Lowry, O. H., Rosebrough, N. J., Farr, A. L. \& Randall, R. J. (I95I). Protein measurement with the Folin phenol reagent. Journal of Biological Chemistry 193, 265-275.

PASTeRnak, C. A. (1962). Sulphate activation and its control in Escherichia coli and Bacillus subtilis. Biochemical Journal 85, 44-49.

QURESHI, M. A. (197I). Genetical and biochemical aspects of the relationship between cysteine and methionine synthesis in Salmonella tymphimurium. Ph.D. Thesis, Birmingham University.

Roberts, R. B., Cowie, D. B., Abelson, P. H., Bolton, E. T. \& Britten, R. J. (1963). Studies of Biosynthesis in Escherichia coli. Washington: Carnegie Institution of Washington Publication 607.

SANDERSON, K. M. (I970). Current linkage map of Salmonella typhimurium. Bacteriological Reviews 34 I76-193.

Sмгтн, D. A. (1971). S-amino acid metabolism and its regulation in Escherichia coli and Salmonella typhimurium. Advances in Genetics 16, I4I-165.

Sмгтн, H. O. (1968). Defective phage formation by lysogens of integration deficient phage P22 mutants. Virology 34, 203-223.

Spencer, H. T., Collins, J. \& Monty, K. J. (1967). Sequential regulation of cysteine biosynthesis in Salmonella typhimurium. Federation Proceedings 26, 677.

VoGel, H. J. \& BonNer, D. M. (1956). Acetylornithase of Escherichia coli: partial purification and some properties. Journal of Biological Chemistry 218, 97-106.

WieBers, J. L. \& Garner, H. R. (1967). Acyl derivatives of homoserine as substrates for homocysteine synthesis in Neurospora crassa, yeast and Escherichia coli. Journal of Biological Chemistry 242, 5644-5649. 